\title{
Teaching Ship Structures with MAESTRO
}

\section{Dr. William M Simpson Jr. P.E., U.S. Coast Guard Academy}

Dr. William M. Simpson, Jr. is an Assistant Professor in the Naval Architecture and Marine Engineering Section of the Engineering Department at the U. S. Coast Guard Academy. He has a Ph.D. in Aerospace Engineering from the University of Maryland, a Masters in Naval Architecture and Marine Engineering from Massachusetts Institute of Technology, and a Bachelor of Science from the U. S. Coast Guard Academy. He is a registered Professional Engineer in the State of Connecticut. He retired from the Coast Guard in 1992 at the rank of Captain having had assignments in Marine Safety, Naval Engineering, Acquisition, and Research and Development. He also served as a faculty member at the Coast Guard Academy while on active duty. His last assignment was as Commanding Officer of the Coast Guard Research and Development Center in Groton, CT. After retirement from active duty, prior to joining the Coast Guard Academy faculty, he worked as an independent naval architect. He is a member of SNAME, ASNE, ASEE, and ABYC.

\section{Capt. Raymond S McCord, Massachusetts Institute of Technology}

\section{Raymond Scott "Chip" McCord, CAPTAIN USN (Ret)}

Chip McCord is a Senior Lecturer in the Mechanical Engineering Department at MIT who teaches graduate courses in Marine Power and Propulsion and Ship Structures. Additionally he is a lab instructor for two undergraduate courses: Design and Manufacturing and Product Engineering Processes. He retired after 30 years of active duty from the US Navy in 2003. He is a graduate of Purdue University with a BS in Engineering and MIT with the SM in Naval Architecture and Marine Engineering and the Ocean Engineer degeree. In the Navy he served at various sea and shore commands as both a line officer and engineering duty officer. In addition to being the Sixth Fleet Salvage Officer and Atlantic Fleet Salvage Officer he served as the twentieth US Navy Supervisor of Salvage from 1994 to 1999. There, among other duties, in 1996 he directed the recovery of victims and wreckage of TWA Flight \#800 off Long Island, NY and in 1998 assisted the Canadian government in the recovery of victims and wreckage of SWISS Air Flight \#111.

Prior to retirement from the Navy he was the Professor of Naval Construction and Engineering in the Department of Ocean Engineering at MIT. 


\title{
Teaching Ship Structures with MAESTRO
}

\begin{abstract}
$\underline{\text { Abstract }}$
Ship structural analysis software, MAESTRO, can be used as a tool in teaching ship structures in both undergraduate and graduate Naval Architecture and Marine Engineering programs. The experience in incorporating MAESTRO into the undergraduate at the U. S. Coast Guard Academy and graduate program at MIT is described. In both programs, the objective is to give students a working knowledge of ship structures without the series of courses and experience needed to become structural analysis experts. Most students of Naval Architecture and Marine Engineering do not specialize in the area of structural analysis nor develop expertize in detailed computerized structural analysis. However, all practicing naval architects and marine engineers need a fundamental working knowledge of ship structures. Traditionally ship structures has been taught by separating the loads into parts and evaluating the responses to the parts as separate problems. This has been adequate to give a basic understanding of ship structures, but, as ship structural design and analysis has moved beyond mere satisfaction of Class Society rules, at least exposure to a more holistic analysis is increasingly important. The specialized ship structural analysis software MAESTRO bridges the gap between simple manual calculations and the major investment in knowledge and time needed to create a valid detailed computerized ship structural model. MAESTRO uses a panel method (modified finite element) tailored specifically for ship structures which requires far less knowledge and time to produce a valid ship structural analysis model. Due to the ease of learning the software and creating a valid ship structural model, it is possible to incorporate its use into general naval architecture courses without the requirement to become an expert in structural finite element analysis. The use of MAESTRO in the graduate program affords the students greater insight into ship structural response to load effects that are not always accurately analyzed by current manual methods (simple prismatic beam analysis). In the undergraduate program, the students use MAESTRO to develop a structural model as part of their senior ship design project. There has been difficulty in the undergraduate program in the development of a whole ship model, but the software allows the mid-portion of the ship structure to be easily created. In both the graduate and undergraduate programs the emphasis is on learning ship structures, not becoming expert in specific software. The authors feel MAESTRO is being used successfully in both the graduate and undergraduate programs to teach ship structures and give students experience in computer structural analysis.
\end{abstract}

\section{Background}

Naval architecture and marine engineering students learn to analyze and design ships. Ships vary greatly in their size and complexity, but they all operate in a challenging environment at the boundary between two mediums. This requires competence in a range of technical engineering 
knowledge areas. These areas include buoyancy, stability, hydrodynamic resistance, motion in waves, weight analysis, accommodations, tankage, propulsion engines and motors, propellers, auxiliary systems, structures, and others. Naval architecture and marine engineering undergraduate education addresses all these knowledge areas, but there is limited course time to devote to any one area. The result is the students must have knowledge in all these areas, but there is not enough time available to develop expertise in all or perhaps any of the areas. At the graduate level, students are expected to have knowledge beyond the undergraduate level in all these areas and develop greater expertise in one or more of these areas.

The knowledge desired in each technical area could be the subject of extensive discussion, but this discussion is focused on the desired knowledge in the area of ship structures. As with all moving vehicles, ships must have adequate structural strength. If the structure is not adequate a catastrophic failure is possible with great economic loss and loss of life. On the other hand, if excess structure is incorporated, the ship will be larger than needed resulting in increased cost and increased fuel consumption over the life of the vessel. This is a compounding problem as additional structure requires a larger hull which requires larger engines which require larger fuel tanks which require a larger ship which requires more structure, etc. This is a part of what is referred to as the ship design spiral (an iterative approach to ship design), and it helps in understanding the importance of having enough but not too much structure. This is shown graphically in figure 1 . below where it can be seen that the structure of the ship both influences and is influenced by many other aspects of the ship.

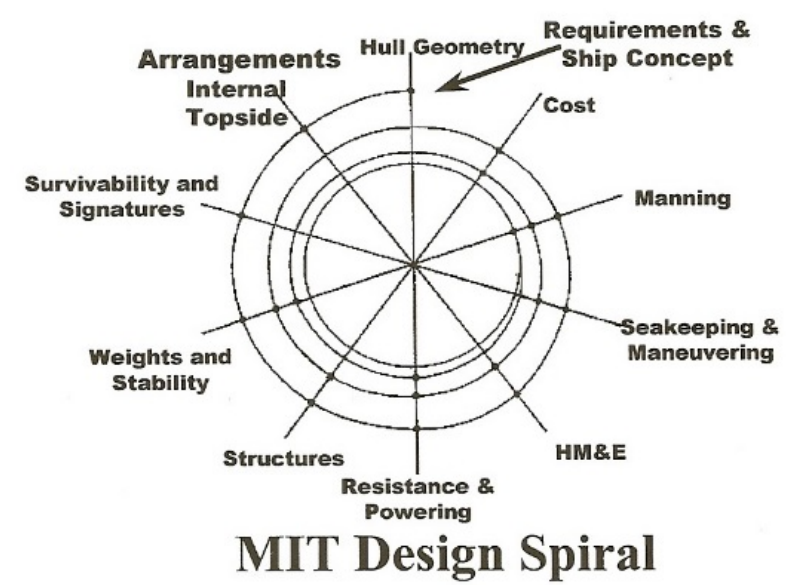

Figure 1.

The hull, decks, and superstructure of a ship serve as both external envelope boundaries and internal subdivision boundaries. They are the structures that maintain and support the integrity of the ship and keeps the ship watertight as they experience static and dynamic loads. This is referred to as a monocoque construction where the external covering carries the structural loads. To simplify the explanation of how this all comes together for ship structures, loads are identified as primary, secondary, and tertiary. The primary loads are global loads on the hull 
viewed as a floating box which is being bent longitudinally. This longitudinal bending is due to the non-uniform longitudinal distribution of weight forces acting downward and buoyancy forces acting up. These forces result in significant stresses in the hull: the bottom, the upper hull decks and the superstructure. To complicate matters the primary stresses can cycle between tension and compression as waves and motions cause buoyant and dynamic forces to change (as great as $10^{8}$ cycles over the life of a ship). This in turn means the hull bottom and the upper decks and superstructure must have acceptable stress levels and adequate resistance to buckling, tearing and fatigue. The secondary stress is identified as the stress in the framing which supports the local loads. For the hull framing the local load is the result of supporting the hull plating as it is pushed in by water pressure on the outside and pushed out by internal forces such as cargo weight and fluid pressure on the inside. For the internal framing the loads come from the weight of the structure itself and internal cargo, equipment, and furnishings. The tertiary stress is the result of the net loads on the hull plating itself due to external hydrostatic pressure and internal liquid pressure. In classical ship structural analysis the primary and secondary stresses are calculated using simple beam theory and tertiary stress is calculated using small deflection plate theory which is available in the form of graphical plots or as a spreadsheet analysis. The three types of stresses are then combined to check the adequacy of the structures. The allowable stress when judging structural adequacy has been based on long experience with successful and unsuccessful ship structures. These allowable stresses and resulting safety factors are incorporated into standards, called "rules", established by ship classification societies, such as the American Bureau of Shipping (ABS), and in engineering specifications by organizations such as the U. S. Navy. Historically the buckling adequacy was maintained by following "rules" for things like plating and frame member thicknesses. Based on experience with conventional ship structure, other loads such as global hull twisting or torsional loads and transverse frame loads were not evaluated except in certain special cases.

Today the classification societies and naval architects still rely on rules and the classical approach for the structural analysis of simple ships and in particular for smaller vessels that are similar to vessels already designed, built, and operating successfully. For larger and/or more complex ships (Navy ships, America's Cup yachts, etc.) with structure that differs from previous designs, full detailed finite element analysis (FEA) together with dynamic load analysis is performed. Due to the complex nature of even a simple ship structure, creating a full FEA model of a ship structure is a very labor intensive undertaking. It requires detailed knowledge and experience with software in terms of creating the model, defining the loads, and interpreting the extremely large output produced.

\section{Undergraduate school use of MAESTRO}

It is in this realm of technical capabilities and complexity our naval architecture and marine engineering students learn their profession. In the undergraduate program at the Coast Guard 
Academy students are taught Statics (basic forces and moments) in a freshman class. In sophomore year they take Mechanics of Materials which teaches the basics of stress, strain, axial stress, bending stress, torsion, shear, column buckling, and a limited exposure to combined stresses. Junior year includes Principles of Naval Architecture in the fall term and Ship Structures in the spring. In the naval architecture course they learn about longitudinal hull girder bending based on distribution of weight and buoyancy and the associated mid-ship section bending (primary) stress. In the ship structures course they learn the classical approach of computing primary, secondary, and tertiary stress and combining them. They also learn to evaluate hull girder shear force and stress and several modes of hull structure buckling resulting from primary stress. It would be appropriate to include a course in structural analysis using FEA, but there is not time in the curriculum for it. Instead, the specialized ship structural analysis software MAESTRO is introduced in the ship structures course. MAESTRO is a modified FEA program developed by Professor Owen Hughes of Virginia Tech and currently maintained by DRS Technologies, Advanced Marine Technology Center where it has been updated and modernized over the years. MAESTRO analyzes ship and ship structures using a panel method (where the panel is in effect an element of the FEA). It was specifically designed for ship structures. Because of this, it is relatively easy for students to use to conduct basic ship structural analysis.

MAESTRO is used in the ship structures course in the design and analysis of a model scale aluminum barge. The aluminum barge project has evolved over several years, but, basically, a group of 3 or 4 students is given a roll of 0.012 inch thick aluminum 20 inches wide and 10 feet long. They are told to design and build a barge that can carry a specified weight. The current tasking is to carry 200 pounds of lead weights. A copy of the project directions is included in Appendix A. An example of a MAESTRO model of a student barge is shown in figure 2.

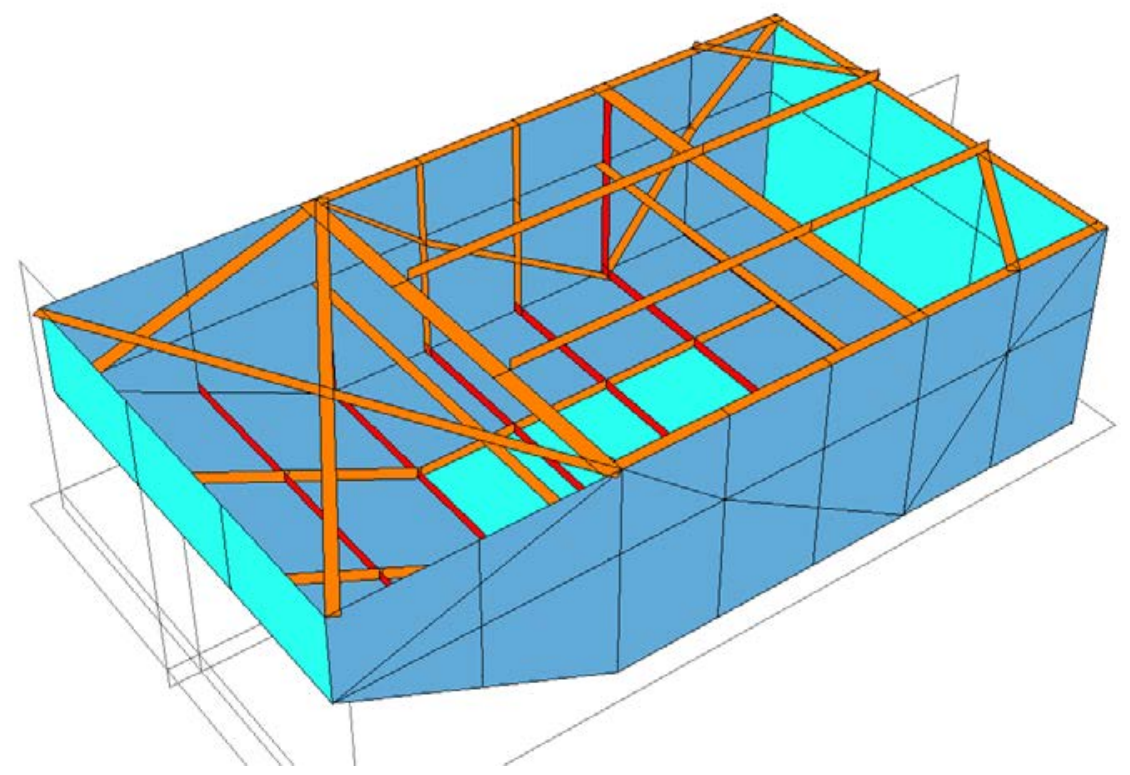

Figure 2. Student Aluminum Barge MAESTRO Model 
Weight is loaded into the student constructed floating barges and $40 \%$ of the grade for the project is based on what percentage of the specified weight they can successfully carry. The majority of the student barges are successful in carrying significant weight, but not all are able to carry the maximum weight. The inability to carry the desired weight varies and is due to structural failures, lack of buoyancy, structural failure, and/or lack of watertight integrity due to poor workmanship. The structural failures seen in the barges are not the kind predicted by classical primary, secondary, and tertiary ship structural analysis.

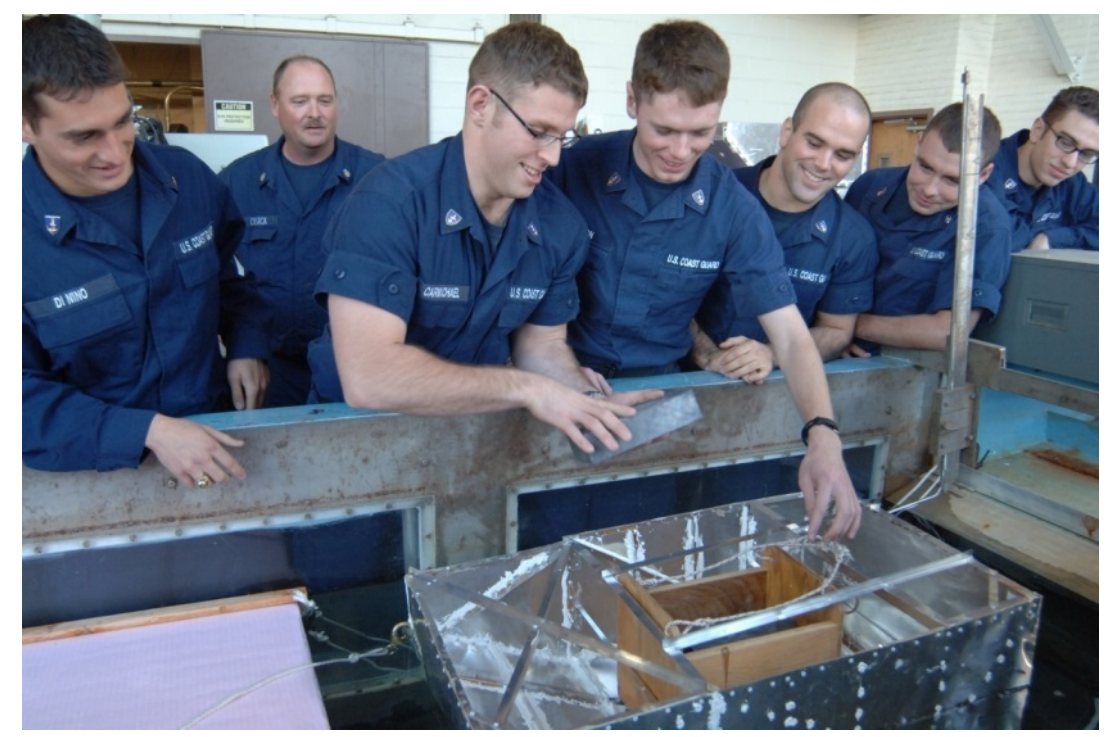

Figure 3. Barge Load Testing

The MAESTRO models of the barges do a good job of predicting the mode, location and at what weight loading structural failure will occur. An example of the agreement between the barge deformation predicted by MAESTRO and the ultimate failure mode in a student constructed barge is shown in figures 4 . And 5 .

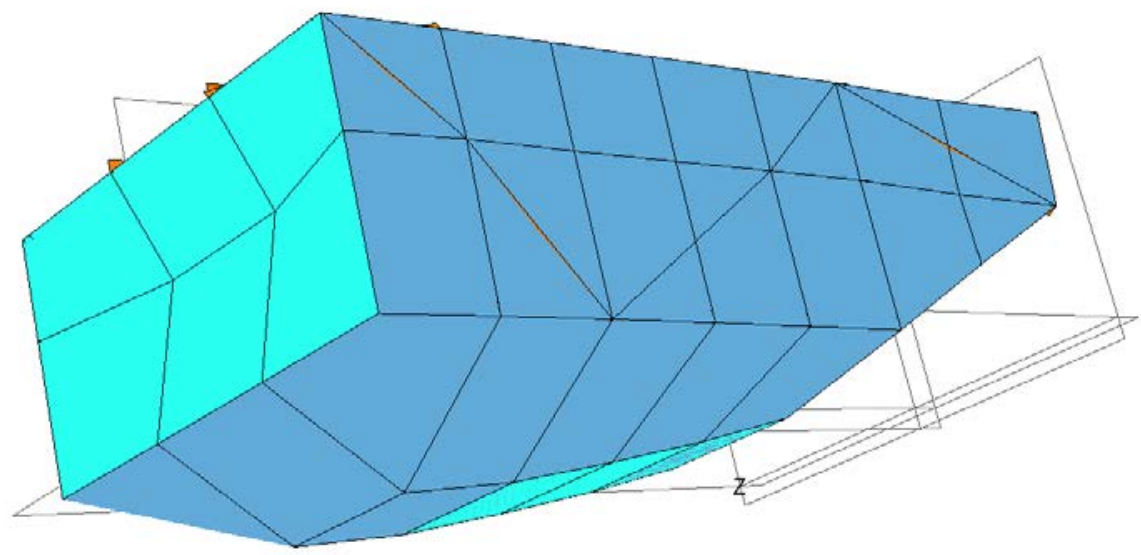

Figure 4. MAESTRO Deformation Prediction 


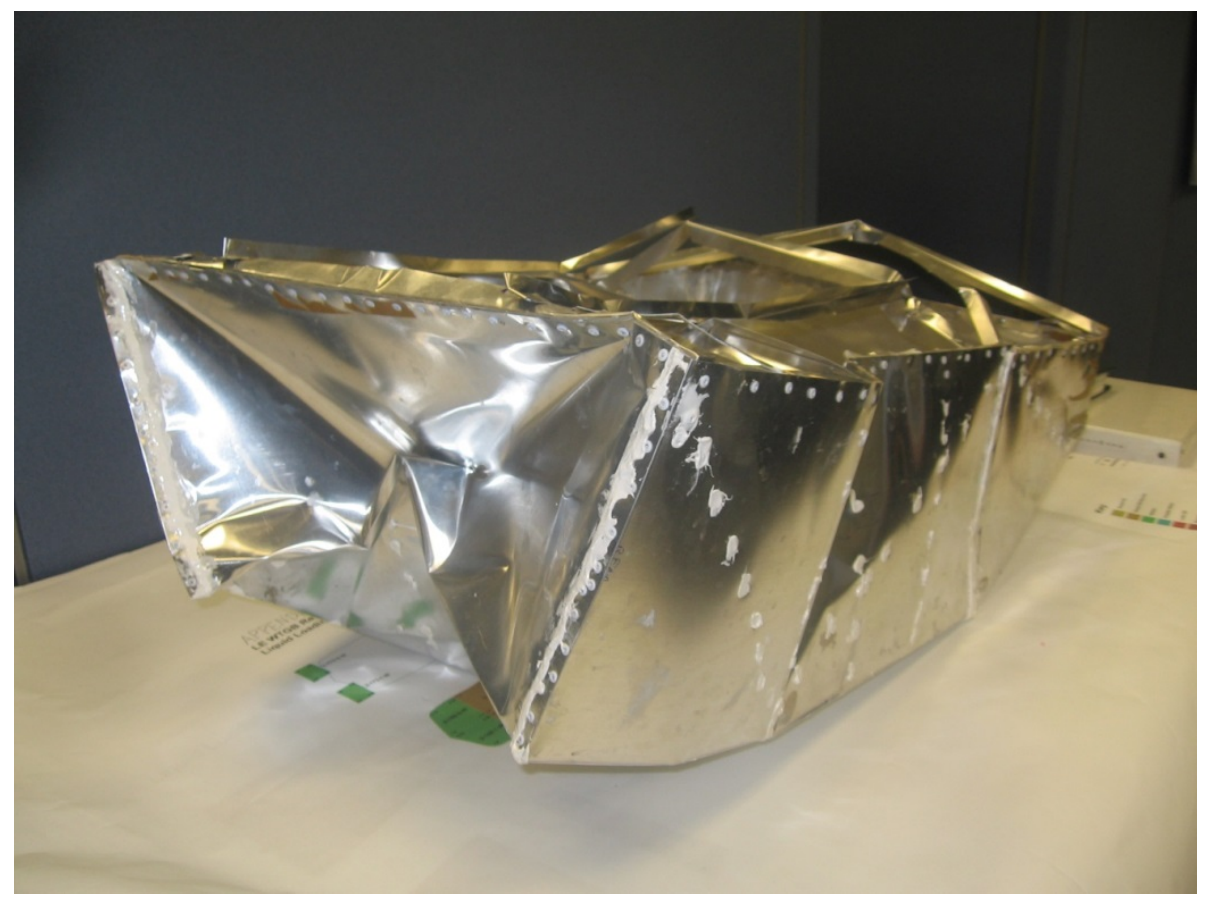

Figure 5. Barge Failure Mode

Currently, modeling and analyzing the barge design in MAESTRO is a project requirement. It is of interest to note that the barge design and construction project was started prior to the introduction of MAESTRO into the ship structure course, and the difference in barge weight carrying ability before and after the inclusion of MAESTRO is significant. The percent of the desired weight successfully carried in the barge testing is shown in the plot below.

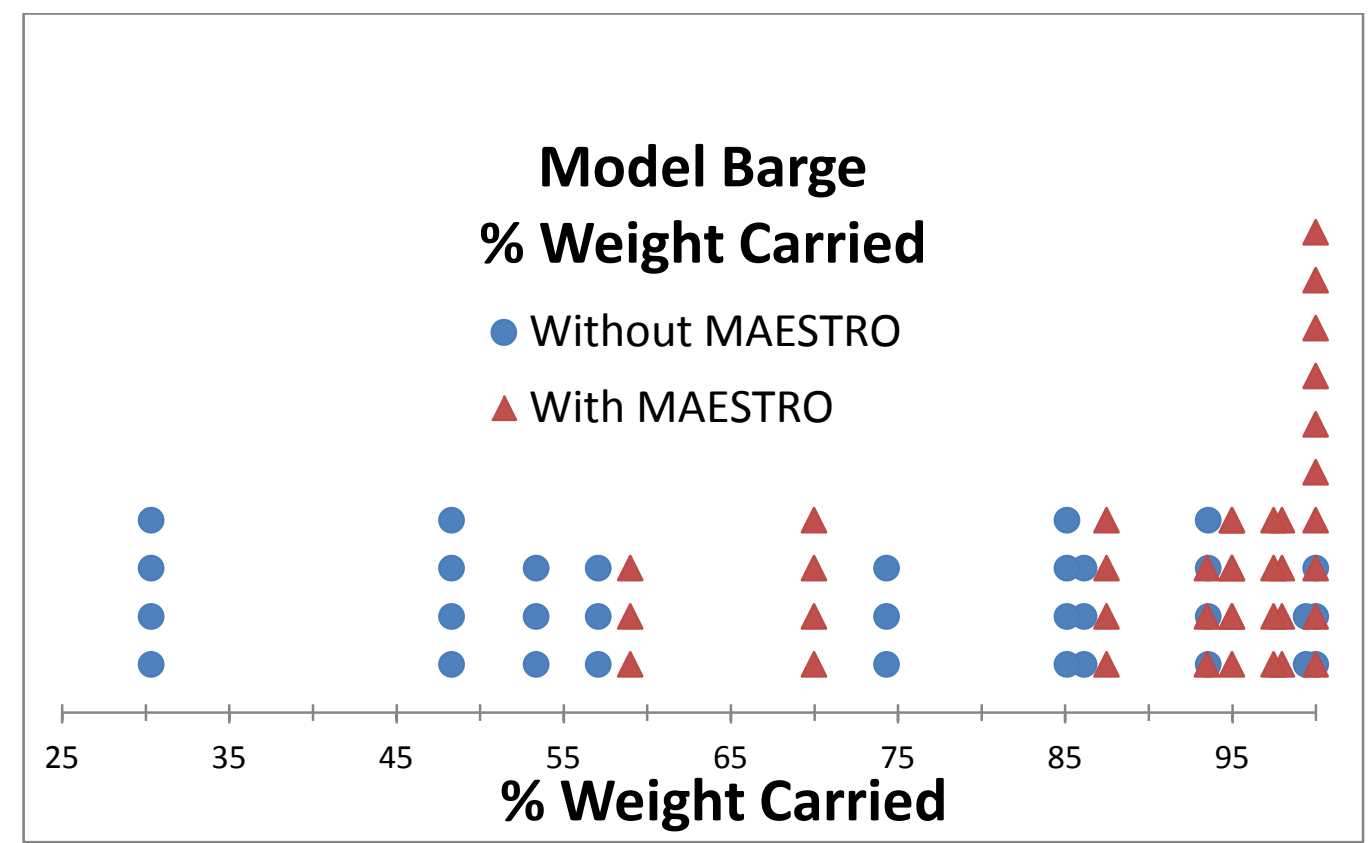


The circular markers show the weight percentage carried for student team members during 2 class years prior to the use of MAESTRO. The triangular markers show the weight percentage carried for student team members for 2 representative years when MAESTRO was used in the design and analysis of the model barges.

It can be seen that the addition of MAESTRO significantly improved weight carrying ability of the barges. This is due to the student's better understanding of the failure modes and thus the structural adequacy of their designs. Not surprisingly some student groups did not take full advantage of MAESTRO but just built their barge and then analyzed it. In a number of these cases they were able to observe in testing that their barge failed just as MAESTRO predicted it would. The student understanding and skill in applying MAESTRO varies, and significant faculty aid is offered to help students model and analyze their designs. The goal is for the students to experience the use of a structural analysis tool, not to become expert in use of MAESTRO.

In the senior year at the Coast Guard Academy the naval architecture and marine engineering students do a two semester ship design project. Over the course of the two semesters they complete the conceptual design of a ship including hull form, arrangements, intact and damage stability, towing tank resistance testing, propulsion system, basic structures, and some auxiliary systems. The students are tasked to produce and analyze a MAESTRO model for their design. The goal of the MAESTRO model is to use weight and buoyancy data from other computer naval architecture software (General Hydrostatic Software, GHS, in this case) to analyze the structure they have designed. If done properly this informs them not only if their structure is adequate, but it validates their original structural weight estimate. An example of a student design project MAESTRO model is shown figure 6.

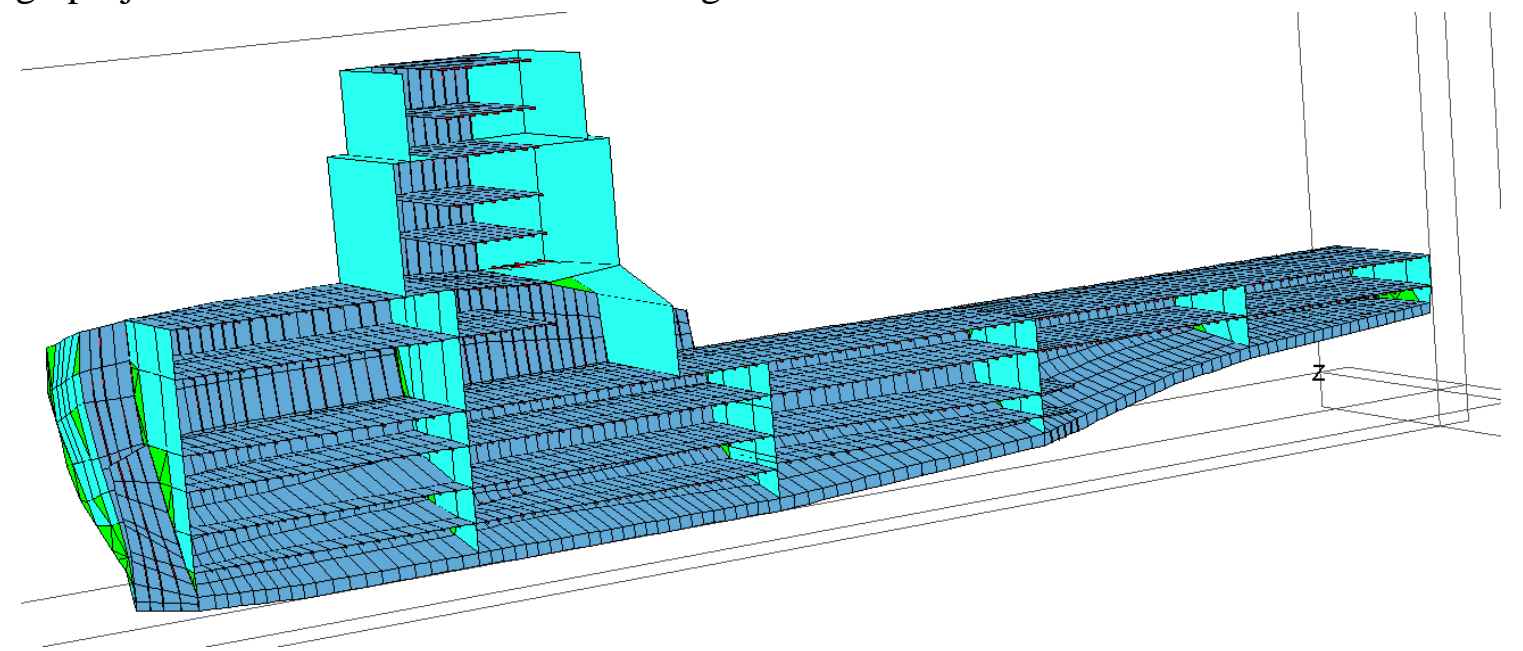

Figure 6. Student Design Project MAESTRO Model

With experience it has been learned that the student effort to develop a full ship model is significant. Modeling the middle portion of the design is relatively easy, but the ends of the ship 
are more difficult to model and require much greater time. Because of this, the current approach is to task the students to model only the middle portion of their design. This results in what MAESTRO terms a cut model, and it provides for weights and end moments to be added. This approach makes it possible for the students to create and evaluate a structural model with reasonable effort. This approach also facilitates student comparison of manually computed midship section stresses with the MAESTRO computed stresses. An example of a student cut model is shown in figure 7.

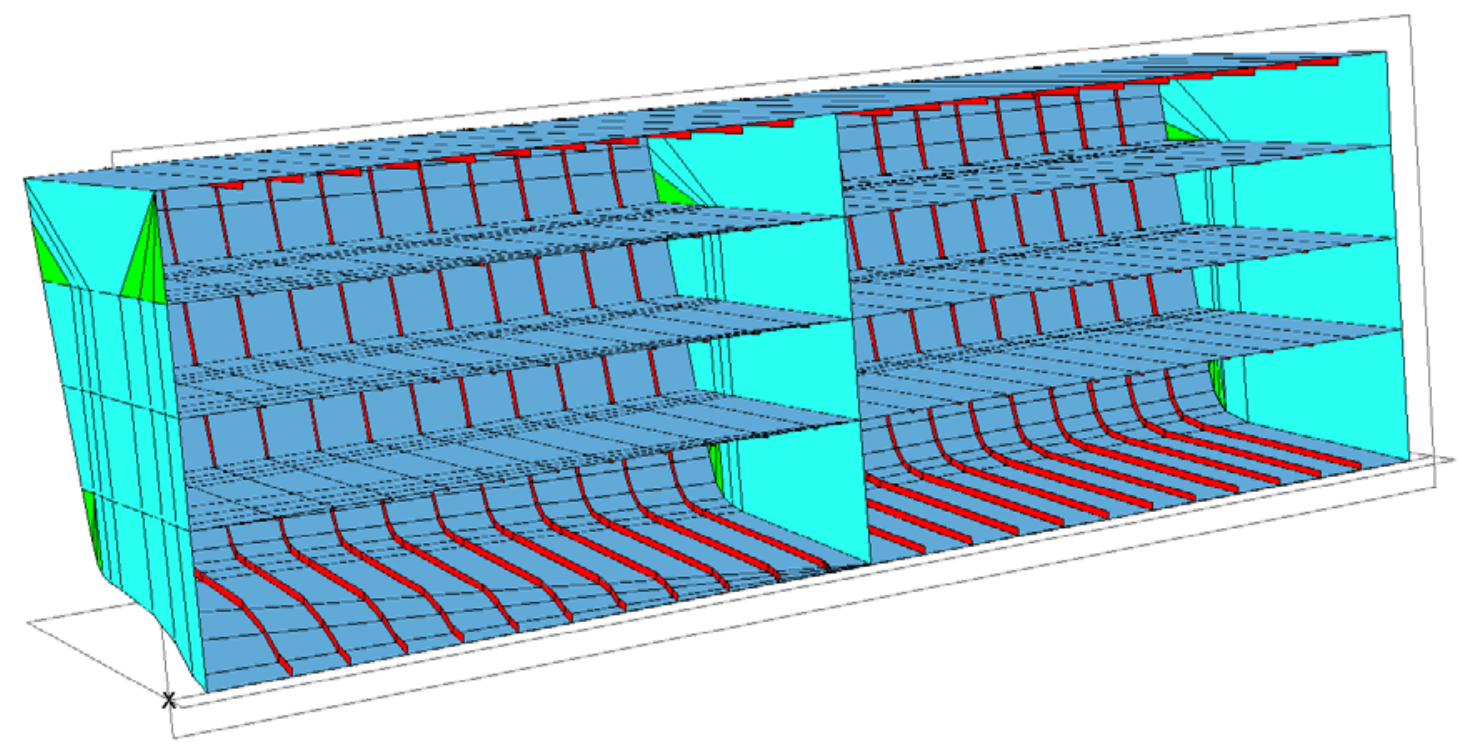

Figure 7. Student Cut Model

\section{$\underline{\text { Graduate school use of MAESTRO }}$}

At MIT, students in the graduate ship design curriculum take courses in naval architecture, marine engineering and ship structures as well as hydrodynamics, acoustics, materials engineering, and design. These are advanced courses where knowledge of basic undergraduate material is required as a prerequisite. The capstone course for the program is a one year design studio where students working in small teams to design a ship. The yearlong design includes a comprehensive structural design and analysis of the project ship.

In the structural course sequence, students take general and advanced structural analysis (i.e., structural mechanics, plates and shells) before taking the Ship Structural Analysis and Design $(S S S A D)$ course. The SSAD course covers the complexity of ship structures: longitudinal strength and hull primary stresses, design limit states including plate bending, column and panel buckling, panel ultimate strength and plastic analysis. Matrix stiffness and an introduction to finite element analysis, as well ultimate ship strength are also investigated. 
The MAESTRO ship structural analysis program is used to introduce students to the FEA method in a computer program tailor made for ships. SSAD is a project based course. In Project \# 1 (Appendix B) students are given a simple box barge to analyze the stresses in the barge's structural members given a specific loading scenario. Students first perform a structural analysis using calculators and simple computer programs (EXCEL, MATHCAD, MATLAB, etc.) that they write. They then use the US Navy's Program of Ship Salvage Engineering (POSSE) to conduct the same analysis. POSSE is a salvage engineering program developed for the US Navy by Herbert Engineering Corp. that determines structural strength using a simple beam theory approach. POSSE is also used to determine stability, ground reaction as well as other items of interest to a salvage engineer.

Both of these first two methods (student derived programs and POSSE) treats the ship as a simple prismatic (uniform) beam floating on the water analyzing only the primary stresses caused by the loading and bending of the hull. Results from these two analyses should be consistent and close. Next, students use MAESTRO to conduct the same structural analysis and compare results to the previous results. Students are given an extensive tutorial/how-to-useMAESTRO to help them get MAESTRO working for this particular project. This saves them a great deal time in making common mistakes and having to learn the MAESTRO program in detail. It should be noted that although MAESTRO is a modified FEA program where it uses large panels as the elements in analyzing a ship structure, it has been modified over the years to give it the capability to analyze any portion of the structure in a fine mesh analysis similar to other FEA computer programs. Students do not use this capability in the SSAD course but can use it when conducting in-depth analysis of the yearlong design project.

Primary stress results in the structural members of the barge vary (as great as 20\%) from the different analyses: simple beam bending method of the first two methods and the modified FEA method of MAESTRO. Students then analyze the results and comment on how the differences of the two methods leads to different results. In the second project for the SSAD course, students analyze the results of project \#1 to determine whether the hull structure is "safe" and efficient, i.e., sufficiently strong enough to carry the loads and not "too" much to be inefficient.

Figure 8. is a screen shot of the modeled barge in MAESTRO. Figure 9. is also a screen shot showing that the stresses from the MAESTRO FEA analysis vary not only in the longitudinal direction but also vary in the transverse direction. This is not the case with the simple prismatic beam approach. 


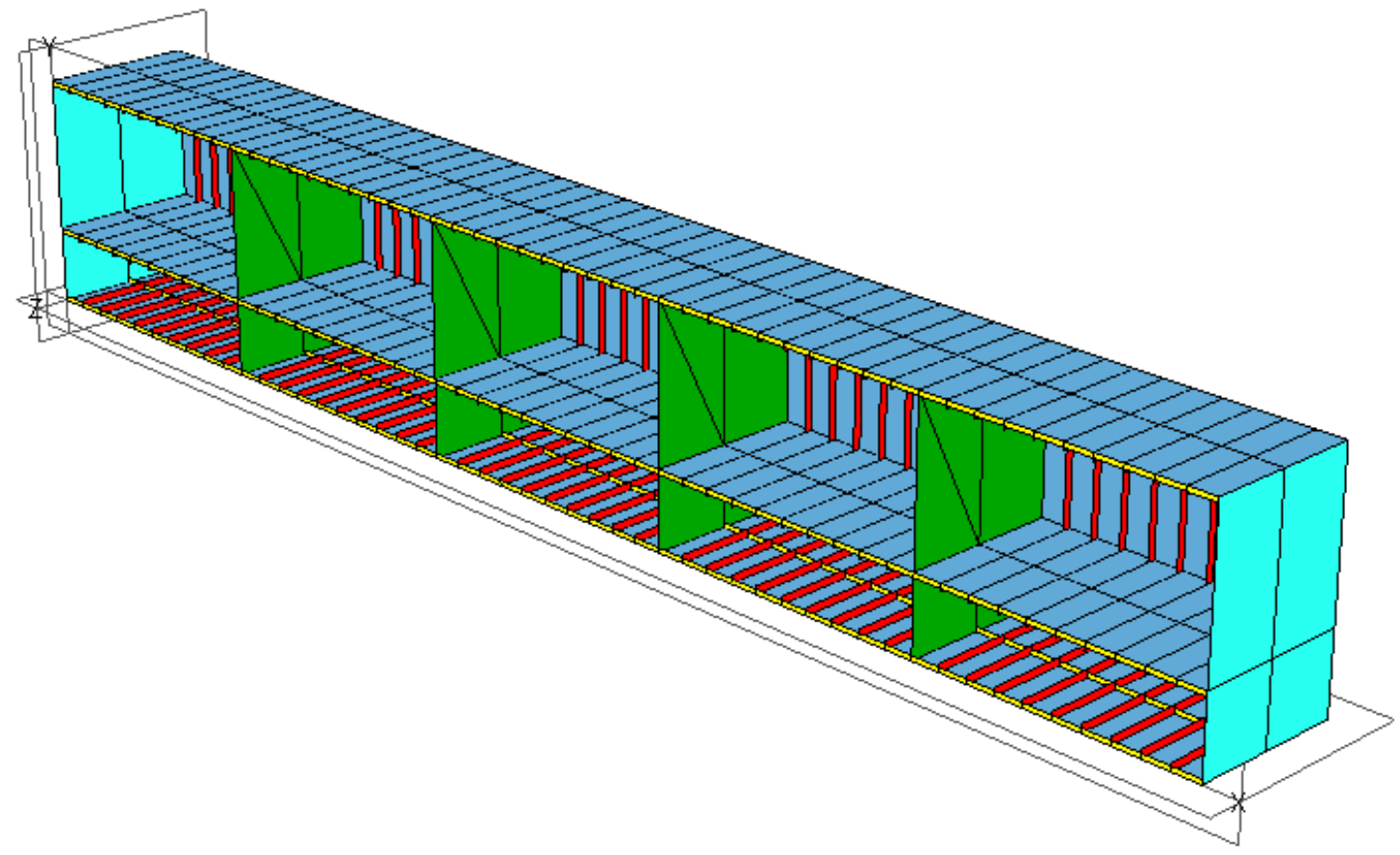

Figure 8. Graduate student assignment simple barge (only port side shown as the barge is symmetric)

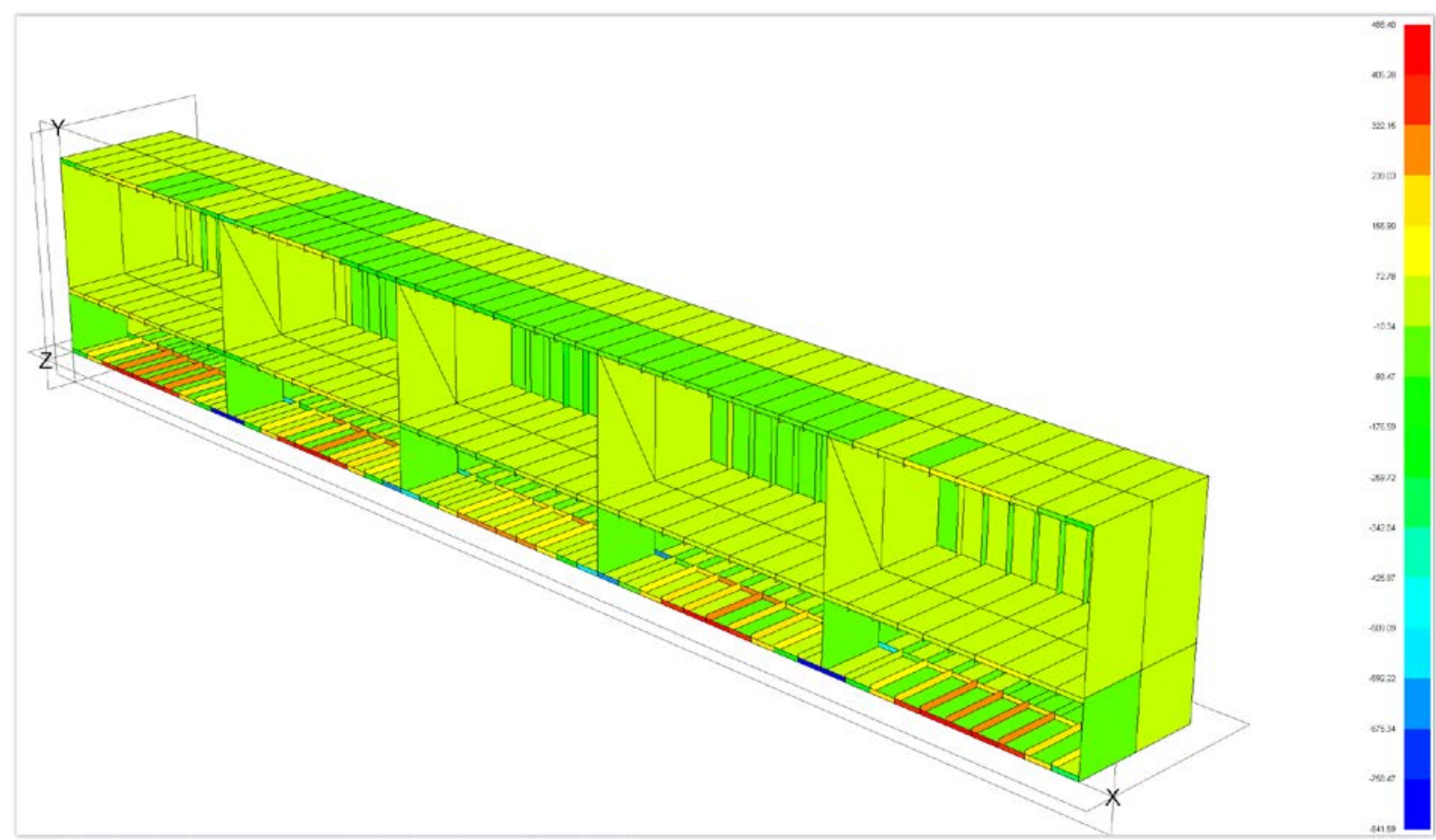

Figure 9. Graduate student assignment results showing stresses in the deck, bottom, sides and main structural elements 


\section{$\underline{\text { Conclusions }}$}

Ship structures is a technical area like many these days that can be analyzed in great detail using computer software producing valid results when the user understands the theory and limitations of the computer program he/she is using. It is extremely important for engineers to be able to validate computer results. Because of that, it is important to continue to teach the simplified classical approach to ship structures. It is also important to expose the students to the power of computerized structural analysis, and how results differ depending on the analyses used and the fidelity of a specific method. MAESTRO's panel approach to ship structures is felt to be an appropriate middle road between the complex detailed FEA modeling of ship structures and the overly simplistic approach of classical ship structural analysis. With MAESTRO the students can understand the benefits (accuracy and detail) of the FEA approach while not having to invest an extraordinary amount of time in modeling a ship in a complicated FEA program. The use of MAESTRO is an important part of the ship structures courses in the undergraduate program at the U.S. Coast Guard Academy and in the graduate program at MIT. In the undergraduate program MAESTRO enables the students to experience the use of computerized structural analysis without the need to develop expertise in complex FEA software. In the graduate program the students are also able to quickly develop structural models in MAESTRO and use it to compare analyses with other simplified approaches. In both cases the students gain experience in the need to check the results from advanced computer analysis with other methods.

\section{$\underline{\text { Acknowledgements }}$}

The authors gratefully acknowledge the support provided by DRS Technologies, Inc. who generously provides academic licenses for the use of MAESTRO by our students.

\section{Disclaimer}

The views expressed here are the authors' and not those of the U. S. Coast Guard Academy, the U. S. Coast Guard, or any other government agency. 


\section{$\underline{\text { References }}$}

1. Hughes, Owen F. \& Paik, Jeom Kee (2010). Ship Structural Analysis and Design, The Society of Naval Architects and Marine Engineers, Alexandria, VA.

2. Simpson, William (2009). Teaching Ship Structures with Sheet Metal, 2009 ASEE Annual Conference, American Society for Engineering Education, Washington, DC.

3. MAESTRO Global Structural Analysis, http://www.maestromarine.com/about.php 
Appendix A

Ship Structures

Spring 2014

Design and Construction Project

Your task is to design and build a sheet metal floating barge to carry up to $200 \mathrm{lb}$. The barge may be open or decked over. If the barge is open it must float with a minimum freeboard of 0.5 in. The weight to be carried will be made up of individual pieces of lead with a base of $3 \mathrm{in}$. by $3 \mathrm{in}$. or smaller.

You will work in groups and each group will design and construct one barge. You may collaborate as you desire with other groups in the design and analysis phases, but you are not to copy the barge design of another group. The actual construction work must be done exclusively by your group members. There are sheet metal tools available in the Power Lab for use in fabricating your barge, and groups are encouraged to share their knowledge in how to use these tools. You will find that, since you are working with metal, precision is important, and the Power Lab tools will be very useful in achieving precision in your construction.

This project will be $10 \%$ of your grade for the course. The points allocated to the various aspects of the project are listed below. You will note that carrying 200 lbs will result in 40 points out of a possible 40 points. There will be no additional points for carrying more than $200 \mathrm{lb}$. You will also note in the point break down that $35 \%$ of the project grade is engineering analysis including a MAESTRO model of your barge. Your MAESTRO model can contribute greatly to a quality design if done early. As in any ship design and construction project properly executed early design work greatly adds to project success. You can of course defer the MEASTRO model and then it will just predict the failure points in your barge after it is built. It will be up to you to manage your work on this project. You can do the design and engineering analysis upfront (good project management), or you can just build a barge and hope it works (you still are required to do the analysis and prepare the computer model). Unfortunately too many real world ship projects begin construction before the design work is done with predictable consequences. You have the opportunity to decide how you want to execute this project. You can design, analyze, and then build or build and then analyze. The choice is yours!

You will be provided the following materials:

1. Aluminum sheet metal 20 inches wide and 120 inches long. The nominal aluminum thickness is 0.012 in (specification: 0.012 in \pm 0.0012 in). It is alloy 3105, 1/2 hard. Material properties for this alloy may be found at: http://www.matweb.com .

2. Pop rivets, $1 / 8$ inch.

3. Silicone Caulk 
No other materials may be used. You may use a reasonable amount of caulk and pop rivets. You may only use the piece of sheet aluminum originally provided. No additional sheet aluminum may be used, and the original piece may not be replaced or traded-in for a fresh piece.

Weight Test

Each barge will undergo a weight trial in the circulating water channel (no water flow). After the desired maximum weight is onboard your barge must float unconstrained for 1 minute without capsizing, or sinking. If your barge has an open top a freeboard of at least $0.5 \mathrm{in}$. must be maintained for the 1 minute. If your barge is decked over, there is no minimum freeboard, but it must remain afloat with the weight for 1 minute. If the barge does not successfully complete the 1 minute test, you may retest with a lesser weight or you may request the instructor's estimate of what the barge might have been able to successfully carry. If there is water leakage but the barge does not sink or capsize, you may, if desired, remove enough weight to achieve the required freeboard with the leakage and accept the new remaining weight as your weight carried.

Deliverables and point values:

1. Design calculations Buoyancy, stability, and structural analysis including MAESTRO model (35 points)

2. Barge (20 points)

3. Weight capacity test ( 0.2 points for each pound of weight carried, max 40 points).

4. One page written summary of results and conclusions (5 points)

\section{Scoring}

It is anticipated that the scoring scheme described is reasonable and fair. However, the instructor may after-the-fact adjust the scoring and points awarded to improve fairness and equity.

Due dates:

1. Design calculations \& MAESTRO model -4 April (If late, -0.5 points/calendar day).

2. Barge / weight capacity testing- Week of 21-25 Apr

3. Written summary - $30 \mathrm{Apr}$ 
$\underline{\text { Appendix B }}$

\subsection{Ship Structural Design and Analysis \\ Project 1 Spring 2014}

Due Date: 6 May 2014

Ref (1): Hughes and Paik "Ship Structural Analysis and Design," 2010.

Ref (2): POSSE 5; POSSE Structural Analysis Steps

Ref (3): MAESTRO 10.0.5; MAESTRO Project \#1 Tutorial

Objective: Using hand calculations, POSSE, and MAESTRO determine and compare Sectional Area, Moment of Inertia, Height of the Neutral Axis, Section Modulus, Shear, Bending Moment, and Bending Stresses on a Barge Structure in still water, and hogging and sagging waves.

This project consists of analyzing a box-barge by hand, and using POSSE and MAESTRO and comparing the results.

\section{Enclosures:}

Figure 1: $\quad$ Barge Dimensions and Loading

Figure 2: $\quad$ Barge Midship $1 / 2$ Cross Section

Table 1: $\quad$ Barge Dimensions

Table 2: $\quad$ Material Properties.

Table 3: $\quad$ Scantlings

Table 4: $\quad$ MAESTRO Endpoints

Table 5: $\quad$ MAESTRO Full Load (displacement 7200MT) Distributed Weights

Table 6: Units/Conversion Factors

Table 7: $\quad$ Results and Comparisons

\section{Part I: Hand Calculations}

Determine the loads, shear and bending moments along the length of the barge using reference (1) as a guide.

\section{Required:}

(A) Determine the Midships Cross Section Area $\left[\mathrm{m}^{2}\right]$, Height of Neutral Axis $\left(\mathrm{h}_{\mathrm{NA}}\right)[\mathrm{m}]$, Moment of Inertia about the neutral axis $\left(I_{\mathrm{NA}}\right)\left[\mathrm{m}^{4}\right]$, Section Modulus top $\left(Z_{D}\right)$ and bottom $\left.\left(Z_{B}\right)\right\}\left[\mathrm{m}^{3}\right]$.

(B) Plot load $[\mathrm{MT} / \mathrm{m}]$, shear $[\mathrm{MT}]$ and bending moment $[\mathrm{MT}-\mathrm{m}]$ along the length for the full load condition in still water.

(C) Determine the maximum shear [MT] and bending moment [MT-m] for still water condition.

(D) Determine maximum stress [MPa] due to bending in still water.

(E) Determine $\mathrm{M}_{\mathrm{w} \text {,Sag }}[\mathrm{MT}-\mathrm{m}]$ from Eqn 3.5.1.b. Assume $C=10.75-[(300-L) / 100]^{1.5}$ applies.

Determine total bending moment, $M_{T, S a g}=M_{W, S a g}+M_{s W}[M T-m]$

(F) Determine $M_{w, H o g}[M T-m]$ from Eqn 3.5.1.a.

Determine total bending moment, $M_{T, H o g}=M_{W, H o g}+M_{s w}$. 
(G) Determine $M_{w \text {, horiz }}[\mathrm{MT}-\mathrm{m}]$ from Eqn 3.5.3.

(H) Determine wave vertical Shear, $Q_{w, v}$ from Eqn 3.5.5. [MT]

Determine total vertical shear $Q_{T, w}=Q_{w, v}+Q_{s w}$. [MT]

(I) Determine minimum value of the section modulus $=Z_{\min }\left[\mathrm{m}^{3}\right]$ from Eqn 3.6.3.

Compare the value with the minimum (deck or keel) section modulus for the barge.

\section{Part II: POSSE Calculations}

Model the barge in POSSE geometrically and structurally using Reference (2) as a guide. Input the full load condition and determine shear, bending moment and stress for still water, hogging and sagging conditions (SW, S, H). All answers are to be in the same units as in part A.

\section{Required:}

(A) Determine the Midships Cross Section Area, Height of Neutral Axis $\left(h_{N A}\right)$, Moment of Inertia about the neutral axis $\left(I_{N A}\right)$, Section Modulus $\left\{\operatorname{top}\left(Z_{D}\right)\right.$ and bottom $\left.\left(Z_{B}\right)\right\}$. Print a picture of the midships section.

(B) Plot full load, shear and bending moment along the length in all three conditions (SW, S, H).

(C) Determine the maximum shear and bending moment in all three conditions (SW, S, H).

(D) Determine maximum stress due to bending in all three conditions (SW, S, H).

\section{Part III: MAESTRO Calculations}

Model the barge in MAESTRO using Reference (3) as a guide. All answers are to be in the same units as in part A.

\section{Required:}

(A) Determine the Midships Cross Section Area, Height of Neutral Axis $\left(h_{N A}\right)$, Moment of Inertia about the neutral axis $\left(I_{N A}\right)$, Section Modulus $\left\{\operatorname{top}\left(Z_{D}\right)\right.$ and bottom $\left.\left(Z_{B}\right)\right\}$.

(B) Plot full load, shear and bending moment along the length in all three conditions $(S W, S, H)$.

(C) Determine the maximum shear and bending moment in all three conditions (SW, $\mathrm{S}, \mathrm{H})$.

(D) Maximum stress in the stiffened panels due to bending in all three conditions (SW, S, H).

(E) Print a picture of the modeled barge.

\section{Part IV: Compare results.}

\section{Required:}

Display (Table 7) and comment on the results obtained in Parts A, B, and C above for all three methods (hand, MAESTRO, POSSE). Compare Midships Cross Section Area, Height of Neutral Axis $\left(h_{\mathrm{NA}}\right)$, Moment of Inertia about the neutral axis $\left(I_{N A}\right)$, Section Modulus $\left\{\right.$ top $\left(Z_{D}\right)$ and bottom $\left.\left(Z_{B}\right)\right\}$, maximum shear, maximum bending moment, and maximum bending stress for still water, sagging and hogging (in the stiffened panels). 


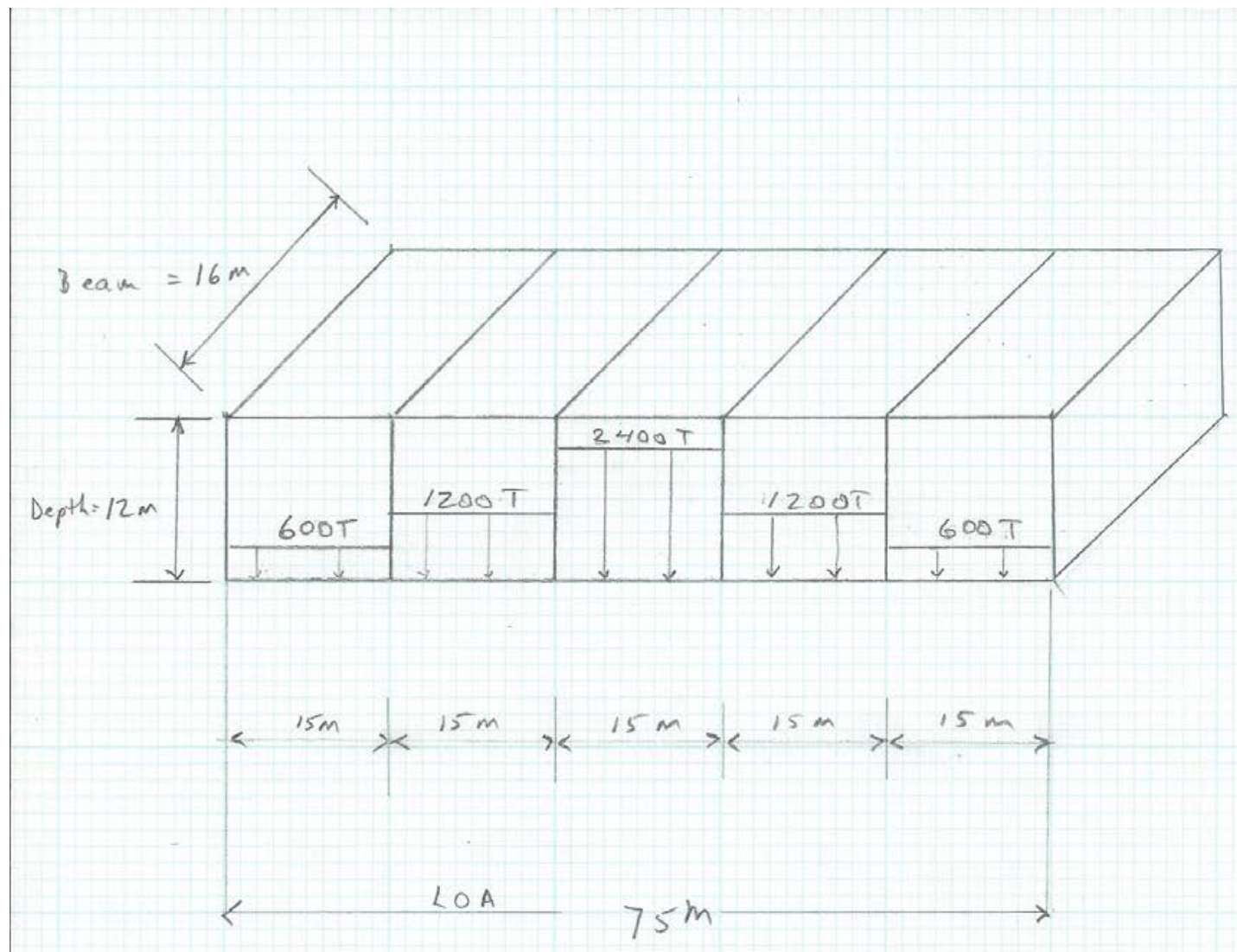

Figure\#

BARGE Dimensious + LOADINS

$$
\begin{gathered}
2.082 \text { Sprins } 2014 \\
\text { Project } \$ 1
\end{gathered}
$$

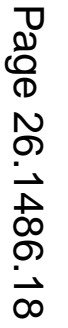




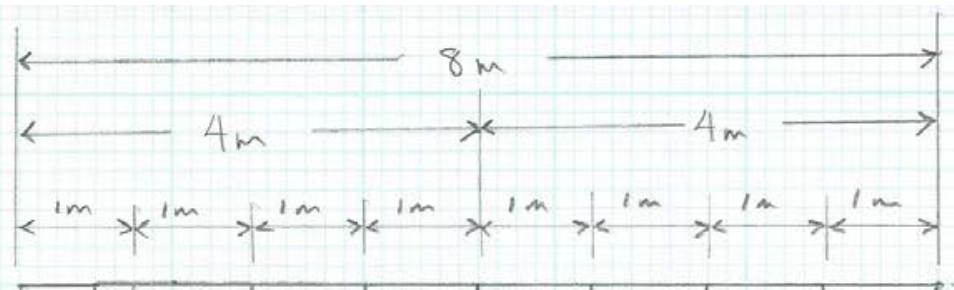

$11111 \perp 1$

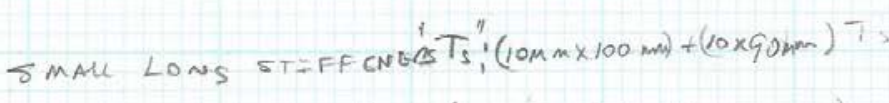
MNDeck + BoTrom" T5: $(10 \times 250)+10 \times 220)$ 2 nd Dele "TS: $(10 \times 230)+(10 * 200)$ ALI MATL. IS MILDSFCES

Znd Bech o Botson stifferent "T" spacing is same as Main de h
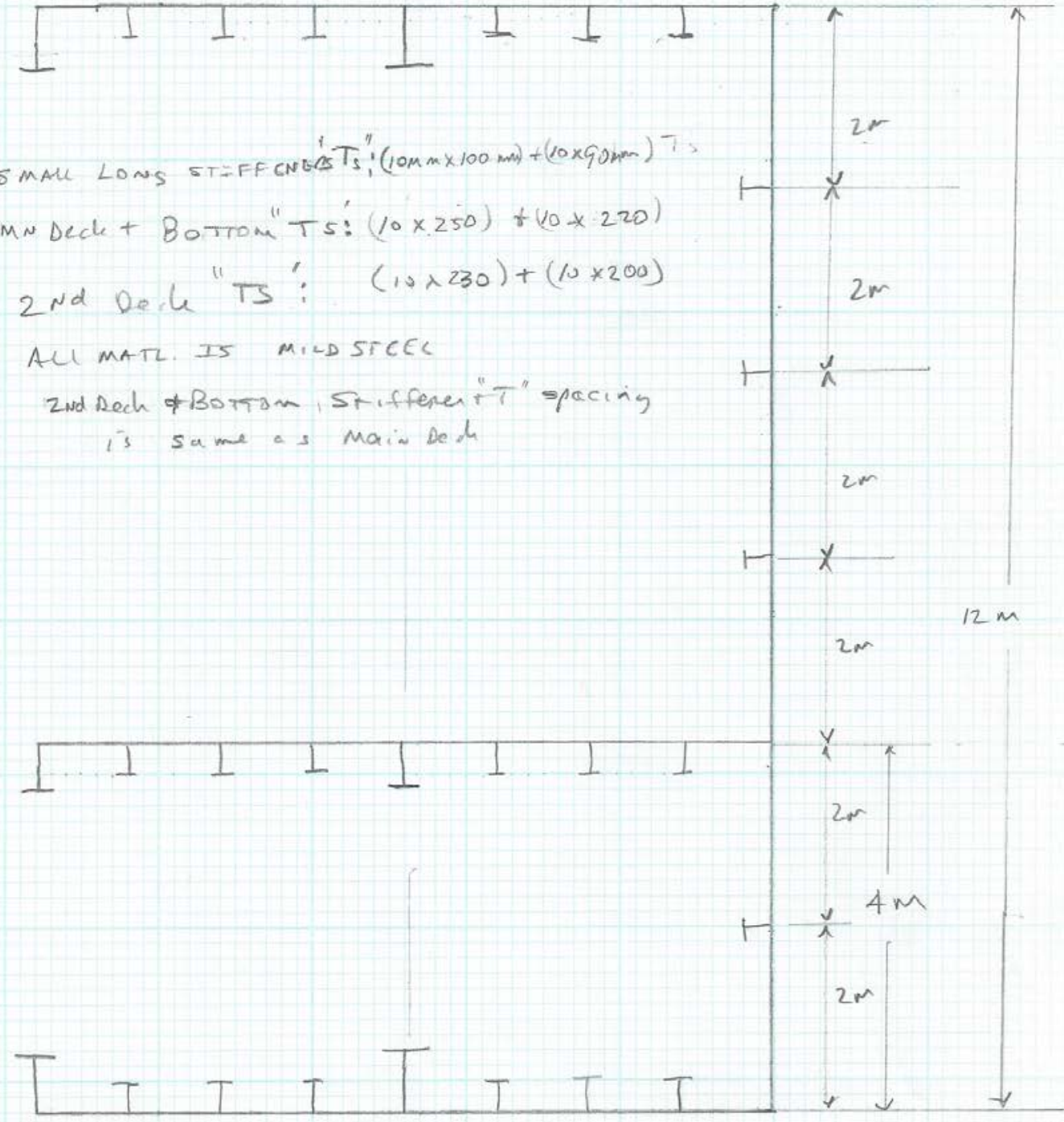

$$
\begin{aligned}
& \text { FiGunE } \# 2 \text { cross Sectise } \\
& \text { B A.RGE Mioship } 1 / 2 \text { cros } \\
& 2.082 \text { SPRING } 2014 \\
& \text { Project } \$ 1
\end{aligned}
$$


Table 1 Barge Dimensions:

$\begin{array}{ll}\text { LOA }=\text { LBP }= & 75 \mathrm{~m} \\ \text { Beam }= & 16 \mathrm{~m} \\ \text { Depth }= & 12 \mathrm{~m}\end{array}$

11 Stations (0-10) with $7.5 \mathrm{~m}$ spacing

Light ship displacement: $\quad$ 1200MT

Full load displacement: $\quad$ 7200MT

Table 2 Material Properties:

Material: Mild steel (MS)

Young's modulus:

Poisson's ratio:

$\mathrm{E}=205 \times 10^{3} \mathrm{MPa}$ psi

Density:

0.3

Yield stress:

$7.85 \mathrm{MT} / \mathrm{m}^{3}$

Ultimate tensile strength:

$235 \mathrm{MPa}$

Reduced yield stress near joints: $235 \mathrm{MPa}$

Weld residual stress ratio:

$400 \mathrm{MPa}$

Proportional limit stress ratio: 1

(NVR) Allowable Bending Stress: $\quad 188 \mathrm{MPa}$

Table $\mathbf{3}$ Scantlings (all material is mild steel):

Plate Thickness: $15 \mathrm{~mm}$ (Side, Deck, Bottom)

Small Longitudinal stiffeners ( $T$ ) (Main deck, bottom, $2^{\text {nd }}$ deck, and side):
Web height:
$\mathrm{h}_{\mathrm{w}}=100 \mathrm{~mm}$
Web thickness:
$\mathrm{t}_{\mathrm{w}}=10 \mathrm{~mm}$
Flange width:
$b_{f}=90 \mathrm{~mm}$
Flange Thickness:
$\mathrm{t}_{\mathrm{f}}=10 \mathrm{~mm}$

Big Longitudinal stiffeners (T) (Main deck, bottom):
Web height:
$\mathrm{h}_{\mathrm{w}}=250 \mathrm{~mm}$
Web thickness:
$\mathrm{t}_{\mathrm{w}}=10 \mathrm{~mm}$
Flange width:
$b_{\mathrm{f}}=220 \mathrm{~mm}$
Flange Thickness:
$\mathrm{t}_{\mathrm{f}}=10 \mathrm{~mm}$

Big Longitudinal stiffeners $(T)\left(2^{\text {nd }}\right.$ deck):

Web height:

$\mathrm{h}_{\mathrm{w}}=230 \mathrm{~mm}$

Web thickness:

$\mathrm{t}_{\mathrm{w}}=10 \mathrm{~mm}$

Flange width:

$b_{\mathrm{f}}=200 \mathrm{~mm}$

Flange Thickness:

$\mathrm{t}_{\mathrm{f}}=10 \mathrm{~mm}$

Transverse T frames:
Web height:
$\mathrm{h}_{\mathrm{w}}=400 \mathrm{~mm}$
Web thickness:
$\mathrm{t}_{\mathrm{w}}=10 \mathrm{~mm}$
Flange width:
$b_{f}=350 \mathrm{~mm}$ 


$$
\begin{array}{ll}
\text { Flange Thickness: } & \mathrm{t}_{\mathrm{f}}=10 \mathrm{~mm} \\
\text { Spacing every } & \mathrm{a}=1.5 \mathrm{~m}
\end{array}
$$

Transverse Bulkheads every $15 \mathrm{~m} ; 15 \mathrm{~mm}$ mild steel.

Table 4 MAESTRO Endpoints:

\begin{tabular}{|l|l|l|l|l|l|l|}
\hline End point & Ref X & Opp X & Ref $Y$ & Opp Y & Ref Z & Opp Z \\
\hline 1 & 0 & 75 & 0 & 0 & 0 & 0 \\
\hline 2 & 0 & 75 & 0 & 0 & -4 & -4 \\
\hline 3 & 0 & 75 & 0 & 0 & -8 & -8 \\
\hline 4 & 0 & 75 & 4 & 4 & -8 & -8 \\
\hline 5 & 0 & 75 & 12 & 12 & -8 & -8 \\
\hline 6 & 0 & 75 & 12 & 12 & 0 & 0 \\
\hline 7 & 0 & 75 & 12 & 12 & -4 & -4 \\
\hline 8 & 0 & 75 & 4 & 4 & 0 & 0 \\
\hline 9 & 0 & 75 & 4 & 4 & -4 & -4 \\
\hline
\end{tabular}

Table 5 MAESTRO Full Load (Displacement: 7200 MT) distributed weights:

Loads:

Block A from FP to station 2:

Block $B$ from station 2 to station 4:

$56 \mathrm{MT} / \mathrm{m}$

Block $\mathrm{C}$ from station 4 to station 6:

$96 \mathrm{MT} / \mathrm{m}$

Block $D$ from station 6 to station 8:

$176 \mathrm{MT} / \mathrm{m}$

Block E from station 8 to station AP:

$96 \mathrm{MT} / \mathrm{m}$

$56 \mathrm{MT} / \mathrm{m}$

Table 6 Conversion factors:

1 meter $\quad=3.281 \mathrm{ft}$

$1 \mathrm{MT}=1000 \mathrm{KG}=0.984 \mathrm{LT}$

$1 \mathrm{KG} \quad=2.205 \mathrm{lb}=9.8066 \mathrm{~N}$

$1 \mathrm{LT} \quad=1.016 \mathrm{MT}$

$1 \mathrm{MT}-\mathrm{m} \quad=3.229 \mathrm{LT}-\mathrm{ft}$

$\mathrm{MT} / \mathrm{m} 2=1.422 \mathrm{psi}$

$\begin{array}{ll}1 \mathrm{~Pa} & =1 \mathrm{~N} / \mathrm{m} 2 \\ 1 \mathrm{kgf} & =9.807 \mathrm{~N} \\ 1 \mathrm{MPa} & =145 \mathrm{psi}\end{array}$




\begin{tabular}{|c|c|c|}
\hline 1 bar & $=1 \times 105 \mathrm{~Pa}$ & $=1 \times 102 \mathrm{KPa}$ \\
\hline $1 \mathrm{MT} / \mathrm{m} 2$ & $=0.009807 \mathrm{~N} / \mathrm{mm} 2$ & $=0.009807 \mathrm{MPa}$ \\
\hline $1 \mathrm{~N} / \mathrm{mm} 2$ & $=101.968 \mathrm{MT} / \mathrm{m} 2$ & $=1 \mathrm{MPa}$ \\
\hline $1 \mathrm{MPa}$ & $=1 \mathrm{MN} / \mathrm{m} 2$ & \\
\hline
\end{tabular}

Table 7 Results and Comparison

Utilize the format of the table below to record and compare results.

\begin{tabular}{|c|c|c|c|c|c|c|c|}
\hline Value & $\begin{array}{l}\text { Hand Calcs / } \\
\text { BV Rules }\end{array}$ & POSSE & MAESTRO & $\begin{array}{l}\text { MAESTRO } \\
\text { unwet ends \& } \\
16 \text { bulkheads }\end{array}$ & $\begin{array}{l}\text { \% Diff } \\
\text { HC/P }\end{array}$ & $\% \operatorname{Diff} \mathrm{P} / \mathrm{M}$ & $\begin{array}{l}\% \text { Diff P/M } \\
\text { unwet ends \& } \\
16 \text { bulkheads }\end{array}$ \\
\hline \multicolumn{8}{|l|}{$\mathrm{h}_{\mathrm{NA}}(\mathrm{m})$} \\
\hline \multicolumn{8}{|l|}{ Area $\left(\mathrm{m}^{2}\right)$} \\
\hline \multicolumn{8}{|l|}{$\mathrm{I}_{\mathrm{NA}}\left(\mathrm{m}^{4}\right)$} \\
\hline \multicolumn{8}{|l|}{$Z_{\text {deck }}\left(\mathrm{m}^{3}\right)$} \\
\hline \multicolumn{8}{|l|}{$Z_{\text {keel }}\left(\mathrm{m}^{3}\right)$} \\
\hline & & & & & & & \\
\hline \multicolumn{8}{|l|}{ Shear sw (MT) } \\
\hline \multicolumn{8}{|l|}{$\mathrm{M} \mathrm{sw}_{\text {sT-m) }}$} \\
\hline \multicolumn{8}{|l|}{ Stress sw $(\mathrm{MPa})$} \\
\hline & & & & & & & \\
\hline Shear sagging (MT) & NA & & & & & & \\
\hline $\mathrm{M}_{\text {sagging }}(\mathrm{MT}-\mathrm{m})$ & NA & & & & & & \\
\hline \multirow[t]{2}{*}{ Stress sagging $(\mathrm{MPa})$} & NA & & & & & & \\
\hline & & & & & & & \\
\hline Shear hogging (MT) & NA & & & & & & \\
\hline $\mathrm{M}_{\text {hogging }}$ (MT-m) & NA & & & & & & \\
\hline Stress hogging $(\mathrm{MPa})$ & NA & & & & & & \\
\hline \multicolumn{8}{|l|}{ IACS \& BV Rules } \\
\hline $\mathrm{M}_{\text {tot agg }}(\mathrm{MT}-\mathrm{m})(\mathrm{BV})$ & & NA & NA & NA & NA & NA & NA \\
\hline $\mathrm{M}_{\text {tot hog }}(\mathrm{MT}-\mathrm{m})(\mathrm{BV})$ & & NA & NA & NA & NA & NA & NA \\
\hline $\mathrm{M}_{\mathrm{w}, \text { horiz }}(\mathrm{MT}-\mathrm{m})$ (BV) & & NA & NA & NA & NA & NA & NA \\
\hline$Q_{\text {tot sag }}(\mathrm{MT})(\mathrm{BV})$ & & NA & NA & NA & NA & NA & NA \\
\hline$Z_{\operatorname{Min}}\left(m^{3}\right)(B V)$ & & NA & NA & NA & NA & NA & NA \\
\hline
\end{tabular}

